\title{
Retraction
}

\section{Retracted: A Design of 45-Degree Dual-Polarization Broadband Plane Station Antenna}

\section{International Journal of Antennas and Propagation}

Received 15 November 2016; Accepted 15 November 2016

Copyright (C) 2016 International Journal of Antennas and Propagation. This is an open access article distributed under the Creative Commons Attribution License, which permits unrestricted use, distribution, and reproduction in any medium, provided the original work is properly cited.

International Journal of Antennas and Propagation has retracted the article titled "A Design of 45-Degree DualPolarization Broadband Plane Station Antenna" [1]. The article was found to contain a substantial amount of material, without citation, from the following published article: Y. Cui, R. Li and P. Wang, "A Novel Broadband Planar Antenna for 2G/3G/LTE Base Stations," in IEEE Transactions on Antennas and Propagation, vol. 61, no. 5, pp. 2767-2774, May 2013. doi: 10.1109/TAP.2013.2244837, where Figures 1, 6, and 8 and Table 1 are identical to Figures 14, 16, and 18 and Table 1 from this article.

\section{References}

[1] J. Zhou, "A design of 45-degree dual-polarization broadband plane station antenna," International Journal of Antennas and Propagation, vol. 2015, Article ID 297521, 9 pages, 2015. 


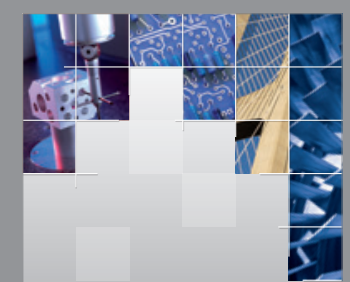

\section{Enfincering}
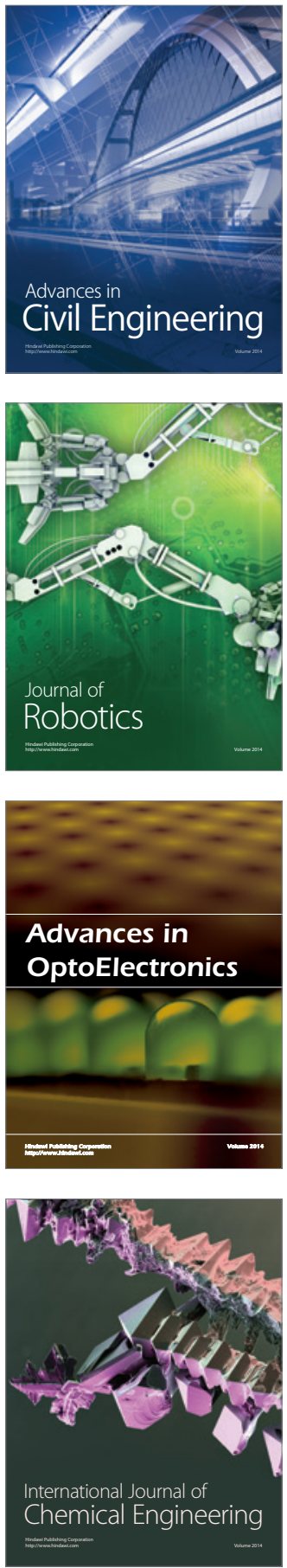

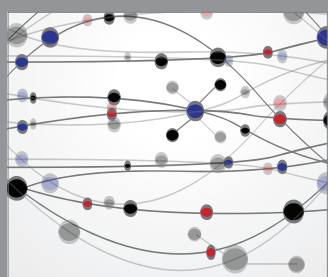

The Scientific World Journal

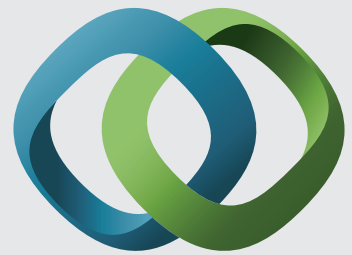

\section{Hindawi}

Submit your manuscripts at

http://www.hindawi.com
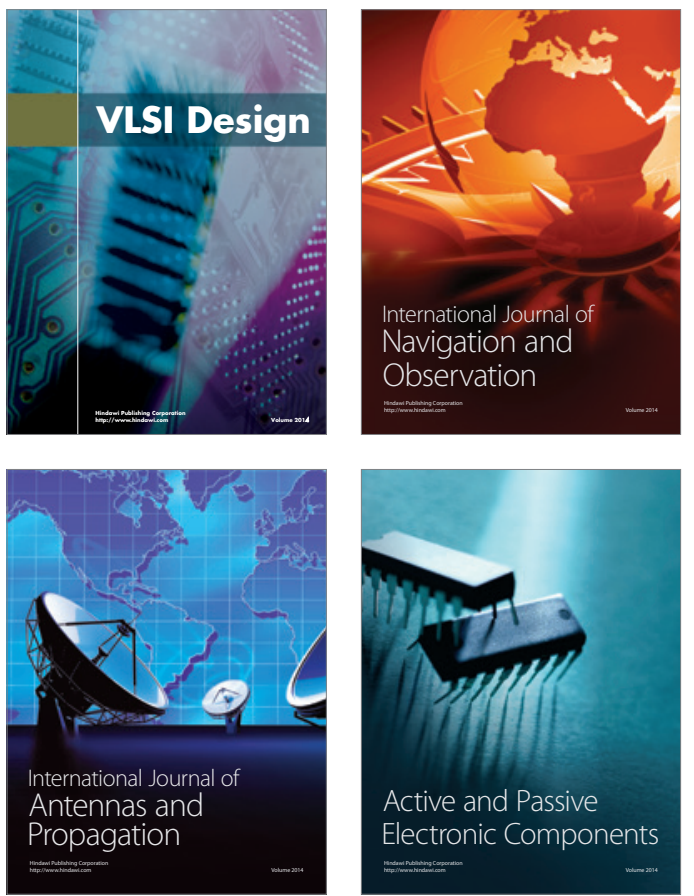
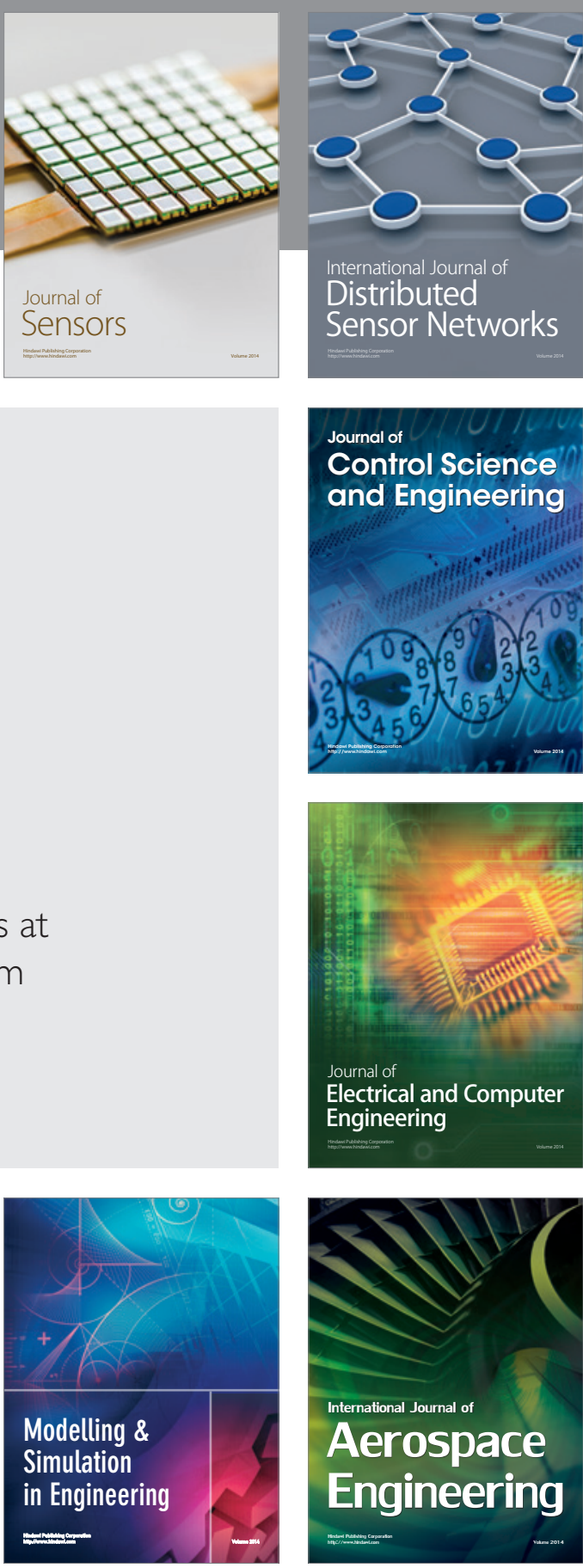

International Journal of

Distributed

Sensor Networks

Journal of

Control Science

and Engineering
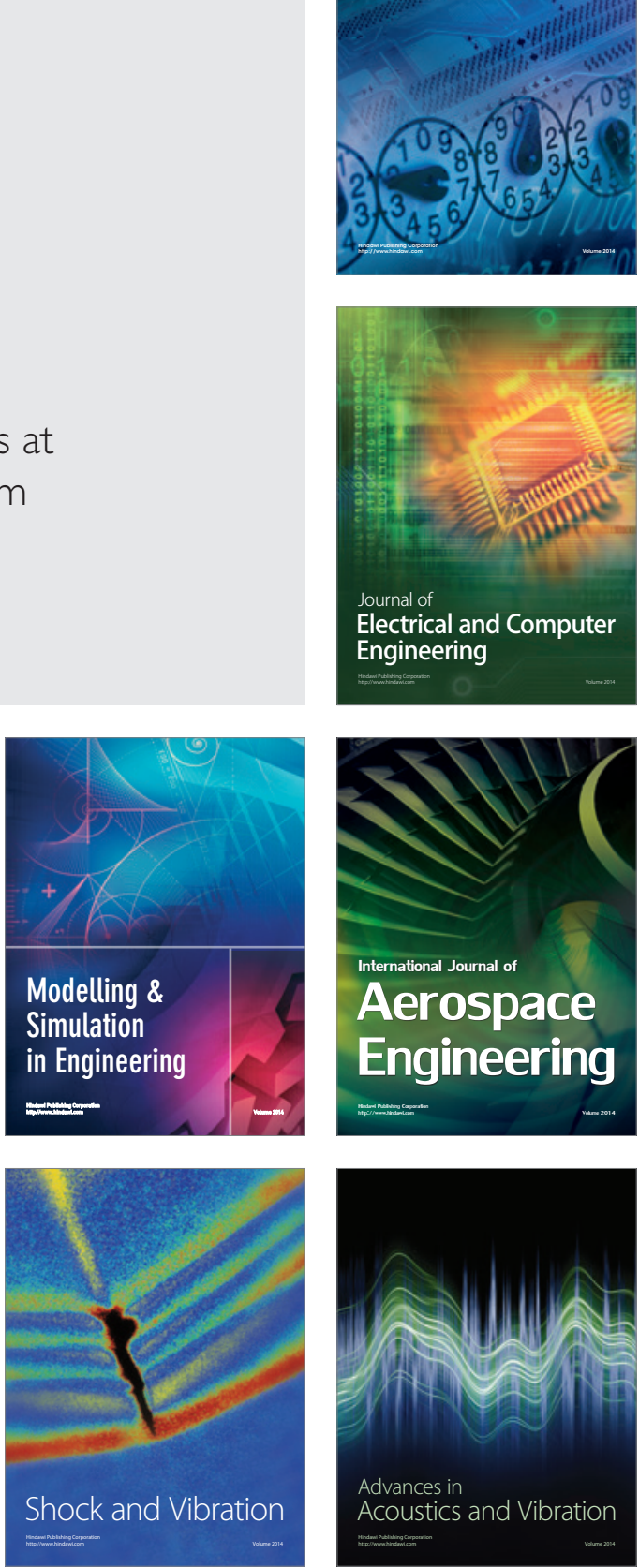